\title{
Modifikasi Zeolit Dengan Tembaga (Cu) Dan Uji Sifat Katalitiknya Pada Reaksi Esterifikasi
}

\author{
Orien Cloudia Handayani Arjek*, Is Fatimah \\ Chemistry Department, Universitas Islam Indonesia KampusTerpadu UII, Jl. Kaliurang Km 14, \\ Sleman, Yogyakarta 55584 \\ *e-mail: orinclaudiahandayani@gmail.com
}

\section{INTISARI}

Telah dilakukan penelitian modifikasi zeolite dengan pengembanan tembaga (Cu) serta aplikasinya sebagai katalis esterifikasi. Modifikasi material dilakukan dengan impregnasi $\mathrm{Cu}$ melalui proses refluks serbuk zeolite dengan larutan $\mathrm{CuSO}_{4} .5 \mathrm{H}_{2} \mathrm{O}$ sehingga konsentrasi $\mathrm{Cu}$ teoretis adalah 5\% dilanjutkan dengan oksidasi dan reduksi padatan. Karakterisasi material dilakukan dengan analisis x-ray diffraction (XRD), Fourier Transform Infra-Red (FTIR) dan pengujian keasaman dari katalis Cu/Zeolit.

Hasil penelitian menunjukkan bahwa tingkat kristalinitas dari Cu-zeolit tidak mengalami perubahan yang signifikan bila dibandingkan dengan zeolit alam. Perubahan terjadi pada intensitas dari puncak yang dihasilkan, seperti pada puncak $2 \theta 27,826^{\circ}$ yang merupakan fasa mordenit pada Cu/Zeolit memiliki intensitas puncak sebesar 1360, sedangkan pada zeolit dengan puncak $2 \theta 27,760^{\circ}$ dengan fasa yang sama meliki intensitas yang lebih kecil yaitu 1048. Pengujian tingkat keasaman dari katalis dilakukan dengan mengadsorbsi piridin ke dalam katalis, kemudian dihitung kadar piridin yang teradsorbsi, pada sampel zeolit kadar piridin yang teradsorbsi sebesar $0,003 \mathrm{~g} / \mathrm{g}$ sedangkan pada sampel Cu/Zeolit sebesar $1,0574 \mathrm{~g} / \mathrm{g}$. Hasil analisis dengan FTIR untuk menunjukkan tingkat keasaman dilihat pada rentang bilangan gelombang antara 1450-1495 $\mathrm{cm}^{-1}$, dari katalis zeolit dengan bilangan gelombang 1491,17 $\mathrm{cm}^{-1}$ intensitas puncaknya (\%T) sebesar 6,53, sedangkan pada Cu-zeolit dengan bilangan gelombang 1468,05 $\mathrm{cm}^{-1}$ intensitas puncaknya (\%T) sebesar 10,99. Pengujian sifat katalitik katalis Cu-zeolit pada reaksi esterifikasi dilakukan dengan meraksikan asam asetat dengan konsentrasi 0,05 mol dan metanol dengan konsentrasi 0,1 mol, kemudian ditambahkan 0,2 gram katalis, kemudian dilakukan proses refluks selama 1 jam. Hasil refluks berupa metil ester kemudian dianalisis menggunakan alat kromatografi gas untuk melihat waktu retensi dan luas area yang dihasilkan. Penggunaan katalis Cu-zeolit menghasilkan ester ditunjukkan dengan munculnya puncak ester.

Key Words: Esterifikasi; Zeolit; Copper

ABSTRACT
Zeolite modification with $\mathrm{Cu}$ has been conducted. Material modification is done by impregnating
$\mathrm{Cu}$ through a zeolite powder reflux process with CuSO4.5H2O solution so that theoretical Cu
concentration is 5\% followed by oxidation and reduction of solids. Material characterization was 
performed by $x$-ray diffraction analysis (XRD), Fourier Transform Infra-Red (FTIR) and acidity testing of $\mathrm{Cu} /$ Zeolite catalyst.

The results showed that the crystallinity level of Cu/Zeolite did not change significantly when compared with natural zeolite. Changes occur at the intensity of the resulting peak, as at the peak of $2 \theta 27.826^{\circ}$ which is the mordenite phase in Cu-zeolite has a peak intensity of 1360, while at zeolite with peak of $2 \theta 27,760^{\circ}$ with the same phase meliki the smaller intensity of 1048. Testing the acidity of the catalyst was carried out by adsorbing pyridine into the catalyst, then calculating the adsorbed pyridine level, in the zeolite samples of pyridine adsorbed by $0.003 \mathrm{~g} / \mathrm{g}$ while in the Cu-zeolite sample of $1.0574 \mathrm{~g} / \mathrm{g}$. The result of analysis with FTIR to show acidity level is seen in the range of wave number between 1450-1495 cm-1, from zeolite catalyst with wave number 1491,17 cm-1 peak intensity (\% T) equal to 6,53, while at Cu-zeolite with wave number $1468.05 \mathrm{~cm}-1$ peak intensity (\% T) of 10.99. Testing of catalytic properties of Cu-zeolite catalyst on esterification reaction was done by taking acetic acid with concentration of 0.05 mol and methanol with concentration of $0.1 \mathrm{~mol}$, then added 0.2 gram of catalyst, then reflux process for 1 hour. The results of reflux in the form of methyl esters were then analyzed by gas chromatography to see the retention time and the area of the resulting area. The use of Cu-zeolite catalysts yielding ester is indicated by the appearance of the ester peak.

Key Words: Esterification; ; Zeolite; Copper

\section{Pendahuluan}

Reaksi esterifikasi merupakan suatu reaksi pembentukan ester dengan mereaksikan secara langsung reagen asam karboksilat dengan suatu alkohol, sehingga didapatkan produk berupa ester. Reaksi esterifikasi pada umumnya dilakukan dengan waktu reaksi yang cukup lama, selain itu pada reaksi ini membutuhkan pelarut organik dalam jumlah besar dan perlu adanya penambahan asam kuat sebagai katalis (Gupta and Paul, 2014).

Reaksi esterifikasi berlangsung dengan menggunakan bantuan katalis yang bertujuan untuk mempercepat reaksi pembentukan metil ester tersebut, selain itu berfungsi untuk meningkatkan selektivitas suatu reaksi. Secara umum, katalis dibagi dalam dua macam yaitu katalis homogen dan katalis heterogen. Beberapa katalis homogen yang sering digunakan dalam proses esterifikasi yaitu asam sulfat $\left(\mathrm{H}_{2} \mathrm{SO}_{4}\right)$, natrium hidroksida $(\mathrm{NaOH}), \quad$ kalium hidroksida $(\mathrm{KOH})$, dan (Anderson \& Boudart, 1981) kalium karbonat $\left(\mathrm{KCrO}_{4}\right)$, sedangkan katalis heterogen yaitu resin penukar kation, hidrotalsit, dan lain-lain ((do Nascimento et al., 2011)). Penggunaan katalis heterogen lebih sering digunakan dalam reaksi dibandingkan katalis homogen, hal ini disebabkan pada faktor kemudahan pemisahan produk dari katalis. Katalis heterogen selain mudah dipisahkan, juga akan lebih ekonomis, sebab katalis dapat diregenerasi dan diguakan kembali pada proses reaksi (Hart and Brown, 2004).

Pemilihan katalis heterogen dalam proses reaksi didasarkan pada karakteristik dari penggunaannya seperti stabil, aktif, mudah diregenerasi, mempunyai kekuatan mekanik, dan sensitif terhadap perubahan panas. Pemilihan katalis yang baik yaitu memiliki luas permukaan komponen yang luas dan mudah dalam pemakaiannya, sehingga dapat dengan mudah mendispersikan komponen aktif pada pengemban atau senyawa penyangga(Asnawati, 2014). Katalis heterogen yang digunakan sebagai 
pengemban atau penyangga, serta telah digunakan secara komersial yaitu zeolit ((Worathanakul and Rakpasert, 2016)).

Zeolit yang digunakan sebagai pengemban adalah zeolit alam, sebab ketersedian zeolit ini di Indonesia sangat besar, serta nilai ekonomisnya lebih kecil dibandingkan dengan zeolit sintetik. Penggunaan zeolit sebagai pengemban karena struktur kristalnya berpori dan luas permukaan yang besar, memiliki stabilitas termal yang tinggi, harganya murah, dan keberadaannya cukup melimpah (Handoko, 2002). Penggunaan zeolit sebagai pengemban berfungsi sebagai tempat logamlogam aktif katalis sehingga dapat dipergunakan secara efektif (Handoko, 2002). Logam yang diembankan ke dalam zeolit dapat meningkatkan aktivitas katalitik agar dapat bekerja dengan baik (Anderson \& Boudart, 1981); selain itu menyebabkan luas permukaan yang relatif besar sehingga reaksi dapat berjalan dengan cepat (Witanto dkk, 2010). Jenis logam yang sering diembankan pada zeolit alam yaitu logam-logam transisi seperti $\mathrm{Cr}, \mathrm{Pt}, \mathrm{Ni}, \mathrm{Mo}$, dan $\mathrm{Cu}$ ((Suseno et al., 2003).

Pemilihan logam tembaga $(\mathrm{Cu})$ dan zeolit dalam penelitian ini didasarkan pada tingkat aktivitas dan selektivitas katalis yang dipengaruhi oleh karakteristik katalis(Trisunaryanti et al., 2005). Karaktristik katalis juga dipengaruhi oleh metode proparasi dan kandungan logam aktifnya. Selain itu preparasi katalis $\mathrm{Cu}$ yang disangga dengan silika pada reaksi dehidrogenasi etanol menunjukan bahwa semakin tinggi suhu rekasi maka aktifitas katalis semakin meningkat(Kim et al., 2001). Penelitian ini bertujuan memodifikasi zeolit sebagai katalis dengan metode refluks, sehingga menghasilkan katalis Cu-Zeolit serta mengkarakterisasi katalis tersebut. Katalis $\mathrm{Cu}$-Zeolit ini kemudian digunakan untuk menguji aktifitas katalitiknya terhadap reaksi esterifikasi.

\section{Metode Penelitian 2.1. Bahan Penelitian}

Bahan penelitian yang digunakan dalam meliputi: zeolit alam asal Klaten, Jawa Tengah, kertas saring Whatman 41, $\mathrm{CuSO}_{4} .5 \mathrm{H}_{2} \mathrm{O}$ piridin, $\mathrm{KBr}$, asam asetat $\left(\mathrm{CH}_{3} \mathrm{COOH}\right)$, dan metanol $\left(\mathrm{CH}_{3} \mathrm{OH}\right)$ buatan Merck, Germany.

\subsection{Alat Penelitian}

Alat penelitian terdiri dari: FourierTransform-Infra Red (FTIR) Perkin-Elmer, XRD Shimadzu X6000, GC Buck Scientific, furnace dan seperangkat alat gelas.

\subsection{Metode Penelitian}

Ditimbang sebanyak 10 gram zeolit 200 mesh kemudian dimasukkan ke dalam labu alas datar dan ditambahkan larutan $\mathrm{Cu}$ asetat dengan konsentrasi 5\% sebanyak 100 $\mathrm{mL}$, lalu dilakukan proses refluks selama 6 jam sampai mendidih. Hasil refluks disaring menggunakan kertas saring dan terbentuk dua komponen yaitu residu dan filtrat. Residu yang terbentuk kemudian dikeringkan menggunakan oven selama satu hari dengan temperatur $600^{\circ} \mathrm{C}$. Bubuk residu yang telah kering, kemudian dimasukkan ke dalam desikator selama semalam. Bubuk kemudian dikalsinasi dengan furnace selama 4 jam pada temperatur $400^{\circ} \mathrm{C}$, kemudian didinginkan di dalam desikator selama semalam. Bubuk $\mathrm{Cu} / \mathrm{zeolit}$ yang disimpan di dalam desikator kemudian dilakukan proses hidrogenasi. Bubuk Zn/zeolit dimasukkan ke dalam reaktor yang sebelumnya telah diisikan glasswool, kemudian dilakukan proses hidrogenasi dengan menggunakan temperatur sebesar $200^{\circ} \mathrm{C}, \quad$ sehingga terbentuklah katalis $\mathrm{Cu} / \mathrm{zeolit} 5 \%$ yang telah di hidrogenasi. Susunan alat hidrogenasi terdapat pada Gambar 1 


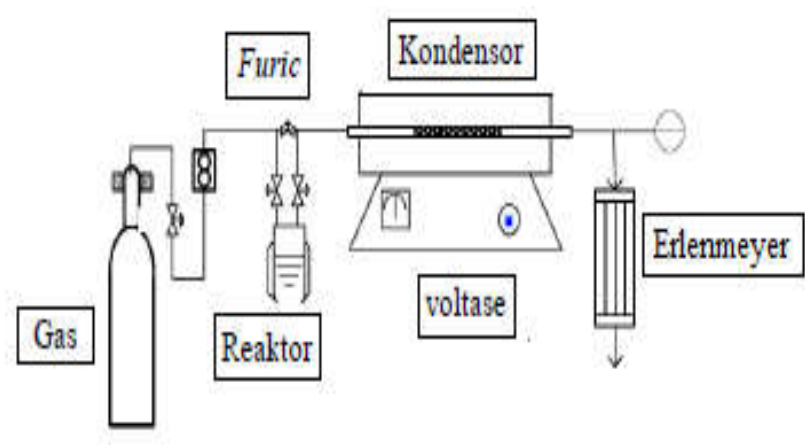

Gambar 1. Skema alat hidrogenasi

\section{Karakterisasi Material}

$\mathrm{Cu} /$ Zeolit dan zeolit dianalisis menggunakan XRD, FTIR dan pengujian keasaman padatan. Analisis sampel dengan XRD ini menggunakan peralatan XRD X6000 dengan sumber radiasi $\mathrm{Cu} \mathrm{Ka}$ dan dengan filter nikel. Data difraksi sinar-X dari sampel yang dianalisis kemudian dibandingkan dengan kartu JCPDS (Joint Committee Powder Diffraction Standard).

Keasaman padatan dilakukan dengan mengukur berat amonia yang diserap oleh padatan selama semalam. Sebanyak sekitar 0,2 g bubuk sampel ditimbang dan ditempatkan pada kurs porselin. Kurs porselin yang telah berisi kemudian dioven selama $1 \mathrm{jam}$ pada temperatur $100^{\circ} \mathrm{C}$. Kurs kemudian disimpan di dalam desikator bersama $10 \mathrm{~mL}$ piridin selama semalam. Kurs didiamkan pada temperatur ruang selama 30 menit, kemudian ditimbang (w2). Sampel bubuk tersebut kemudian dianalisis menggunakan FTIR. Penentuan keasaman dari katalis dapat dihitung menggunakan persamaan

Keasaman $=\frac{\left(w_{\mathrm{n}}-\mathrm{w}_{1}\right)}{\text { mas5a sampel }} \mathrm{g} / \mathrm{g}$

Dengan:
$\mathrm{W}_{1}$ : massa awal sampel

w2: massa akhir akhir sampel

Analisis FTIR terhadap sampel dilakukan dengan menyiapkan sampel dalam bentuk pelet bersama $\mathrm{KBr}$. Spektrum direkam pada rentang bilangan gelombang 400-4000 $\mathrm{cm}^{-1}$ (Faghihian and Mohammadi, 2014).

Penentuan sifat katalitik Cu-zeolit pada reaksi esterifikasi

Sebanyak 2,86 mL asam asetat glasial untuk membuat asam asetat 0,05 mol, sebagai larutan pertama. Sebanyak $4 \mathrm{~mL}$ metanol p.a untuk membuat metanol 0,1 mol, sebagai larutan kedua. Dimasukkan larutan pertama dan kedua kedalam labu alas datar dan ditambahkan katalis sebanyak 0,2 gram, kemudian direfluks selama 1 jam pada temperatur. Hasil refluks kemudian disaring dan dianalisis menggunakan GC (Gas Chromatography), serta diukur nilai retensi dari metanol dan asam asetat glasial sebagai standar.

\section{Hasil dan Pembahasan}

Pola difraksi dari karakterisasi zeolit 200 mesh dan Cu-zeolit menggunakan XRD ditampilkan pada Gambar 2.

Difraktogram hasil uji XRD menghasilkan empat puncak Bragg indeks Miller tunggal dengan intensitas yang cukup tinggi pada daerah skala sudut $2 \theta: 10^{\circ}-27^{\circ}$, dimana pada sudut ini akan membedakan puncak pada fasa mordenit dan fasa klinoptilolit dengan jelas, sedangkan pada skala sudut $2 \theta$ diatas $27^{\circ}$ memiliki puncak Bragg yang ganda dan lebar, indeks Miller (indeks fasa) yang bertumpukan, sehingga sulit mengidentifikasi puncak yang terbentuk. Puncak Bragg dari difragtrogram $\mathrm{Cu}$-zeolit yang merupakan milik dari fasa mordenit terletak pada pada sudut $2 \theta: 13,66^{\circ}$ 
dan $27,826^{\circ}$ dengan bidang masing-masing (930) dan (1360), sedangkan untuk fasa klinoptilolit terletak pada sudut $2 \theta: 22,36^{\circ}$ dan $25,801^{\circ}$ dengan bidang (1272) dan (1129). Puncak yang membedakan secara lebih spesifik antara fasa mordenit dan klinoptilolit terletak pada sudut $2 \theta 22,385^{\circ}$, bidang (1272) yang merupakan milik fasa klinoptilolit, serta sudut $2 \theta 27,826^{\circ}$, bidang (1360) yang merupakan milik fasa mordenit.
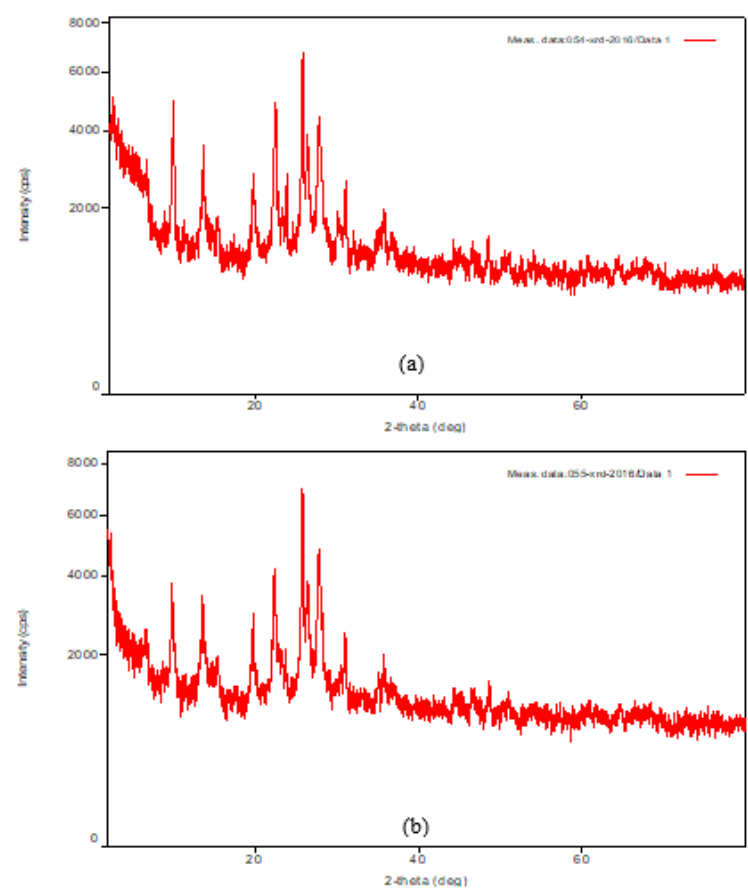

Gambar 2. Difraktogram hasil analisis dengan XRD a. zeolit b. $\mathrm{Cu} /$ Zeolit

Gambar 2 menunjukkan pola difraktogram dari zeolit hampir sama dengan pola difraktogram $\mathrm{Cu} /$ Zeolit, akan tetapi terjadi peningkatan intensitas setelah dilakukannya pengembanan $\mathrm{Cu}$ ke zeolit 200 mesh. Berdasarkan hasil pengembanan yang dilakukan, dapat diperoleh bahwa kristalinitas dari zeolit 200 mesh tidak mengalami kerusakan setelah ditambahkan tembaga $(\mathrm{Cu})$. Hal ini telihat dari terbentuknya puncak-puncak yang kuat dan spesifik pada difraktogram zeolit dan
$\mathrm{Cu} /$ Zeolit. Hasil analisis menunjukkan nilai $2 \theta$ dan d logam tembaga $(\mathrm{Cu})$ mengalami perubahan yang cukup signifikan setelah dilakukannya perlakuan secara hidrotermal pada zeolit menjadi $\mathrm{Cu}$-zeolit.

Perubahan sifat permukaan padatan terjadi ditunjukkan dengan perubahan keasaman padatan sebagaimana disajikan pada Tabel 1.

Tabel 1. Hasil uji keasaman pada katalis

\begin{tabular}{c|c}
\hline Sampel & Keasaman $(\mathbf{g} / \mathbf{g})$ \\
\hline Zeolit & 0,0030 \\
$\mathrm{Cu} /$ Zeolit & 1,0574 \\
\hline
\end{tabular}

Dari Tabel 1, terlihat bahwa keasaman $\mathrm{Cu} /$ Zeolit lebih besar daripada zeolite. Hal ini dapat disebabkan oleh proses dealuminasi zeolite dengan proses hidrotermal yaitu proses kalsinasi dan reduksi dari katalis zeolit. Proses hidrotermal meliputi pelepasan aluminium dari kerangka zeolit, aluminium tersebut akan pindah atau berada pada struktur kerangka dan akan menempel pada permukaan dan pori-pori zeolit sehingga proses adsorpsi basa piridin pada permukaan zeolite menjadi lebih efektif. Proses pemasukan situs aktif asam bronsted dan asam lewis pada kerangka zeolite ini dimungkinkan terjadi sebab pada kerangka zeolite tersebut tidak memiliki unsur yang bermuatan positif.

Kenaikan keasaman ini sesuai dengan hasil pengujian FTIR. Uji keasaman sampel dilakukan dengan mengadsorpsi piridin kedalam katalis. Jumlah piridin yang teradsorpsi dianalisis dengan menggunakan spektroskopi inframerah, dengan mengamati daerah serapan yang terbentuk. Pita adsorpsi piridin dapat diamati pada daerah $1400 \mathrm{~cm}^{-1}$ $1700 \mathrm{~cm}^{-1}$ yang berkorelasi langsung dengan situs asam bronsted dan situs asam lewis 
pada kerangka zeolit. Interaksi piridin dengan sisi situs asam Brønsted, akan ditandari dengan molekul piridin yang terprotonasi dan teradsorpsi pada bilangan gelombang spesifik sekitar $1640 \mathrm{~cm}^{-1}$ (Fatimah et al., 2014) Interaksi piridin dengan sisi situs asam lewis, ditandai dengan pembentukan kompleks ikatan koordinasi antara pasangan elektron bebas dari molekul pridin dengan orbital kosong dari permukaan padatan zeolit dan teradsorpsi pada bilangan gelombang spesifik sekitar $1450 \mathrm{~cm}^{-1}-1455$ $\mathrm{cm}^{-1}$.
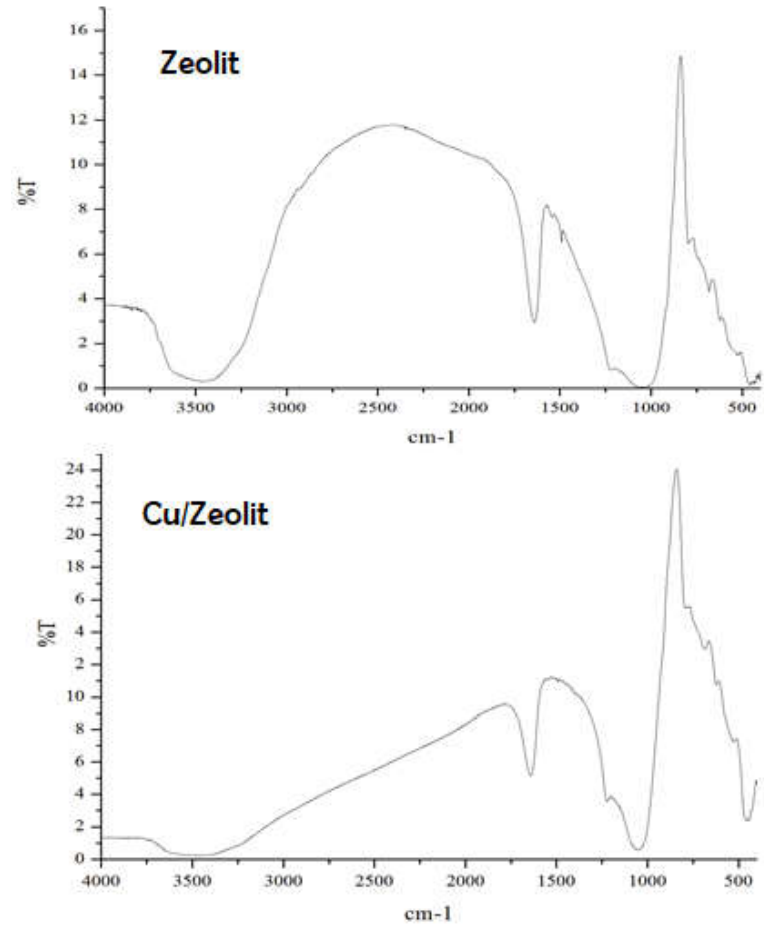

Gambar 3. Spektrum FTIR zeolit dan $\mathrm{Cu} /$ Zeolit setelah mengadsorpsi piridin

Gambar 3(zeolit) memperlihatkan pita adsorpsi pada bilangan gelombang disekitar $1642,71 \mathrm{~cm}^{-1}$ dengan \%T sebesar $5,15 \%$ yang menunjukkan sisi pada situs asam Brønsted, sedangkan pita serapan pada bilangan gelombang 1468,05 dengan \%T
10,99\% menunjukkan sisi asam lewis. Berdasarkan Gambar 3 diperoleh bahwa semakin kecil dari rasio $\mathrm{SiO}_{2} / \mathrm{Al}_{2} \mathrm{O}_{3}$, maka intensitas pita adsorpsi pada situs asam Brønsted dengan bilangan gelombang sekitar $1640 \mathrm{~cm}^{-1}$ semakin tinggi, sehingga jumlah pembentukan asam Brønsted pada katalis $\mathrm{Cu}$-zeolit semakin meningkat.

Penentuan sifat katalitik Cu-zeolit pada reaksi esterifikasi dilakukan dengan melakukan serangkaian analisis berdasarkan penerapan pada reaksi esterifikasi. Proses analisis dilakukan dengan mereaksikan asam karboksilat dengan metanol pada temperatur didihnya yaitu sekitar $65-70^{\circ} \mathrm{C}$, yang ditambahakan katalis Cu-zeolit, kemudian direfluks selama 1 jam pada temperatur didih yang ditentukan. Reaksi yang terjadi pada proses refluks yaitu

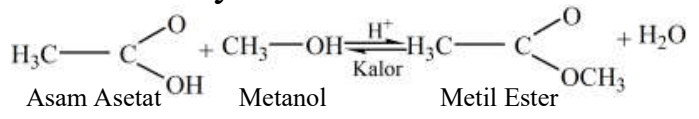

Gambar 4. Reaksi esterifikasi

Penentuaan sifat katalitik $\mathrm{Cu} /$ Zeolit pada reaksi esterifikasi dilakukan dengan mereaksikan asam asetat $0,05 \mathrm{~mol}$ dengan metanol 0,1 mol, kemudian dilakukan refluks selama 1 jam dengan ditambahkan katalis zeolit dan $\mathrm{Cu}$-zeolit sebanyak 0,2 gram. Proses esterifikasi didasarkan pada hasil berupa metil ester, dimana proses reaksi esterifikasi ini dipengaruhi oleh katalis yang menyediakan ion $\mathrm{H}^{+}$(ion hydronium) untuk mempercepat proses reaksi terjadi. Ion $\mathrm{H}^{+}$ yang digunakan pada penelitian ini diberikan oleh katalis zeolit dan Cu-zeolit. Perbedaan dari besarnya luas area yang dihasilkan oleh puncak-puncak retensi yang dihasilkan, yang pada penelitian ini didasrkan pada puncak retensi dari metil ester. Puncak retensi ini diperoleh dari hasil analisis dengan menggunakan alat kromatografi gas. Prinsip 
dari analisis menggunakan alat kromatografi gas yaitu pemisahan senyawa yang didasarkan pada dua fasa yang berbeda, dengan dipengaruhi oleh fasa gerak berupa gas dan fasa diam berupa kolom yang berisi silika gel. Hasil dari analisis menggunakan alat kromatografi gas ditampilkan pada Tabel 2.

Tabel 2. Pengukuran metil ester dengan kromatografi gas

\begin{tabular}{cc}
\hline Katalis & \% metil asetat \\
\hline Zeolit & 21,92 \\
Cu-zeolit & 24,29 \\
\hline
\end{tabular}

Berdasarkan Tabel 2 katalis $\mathrm{Cu} /$ Zeolit memberikan hasil metil asetat lebih besar dibandingkan zeolit. Berdasarkan pengujian sebelumnya mengenai tingkat keasaman dari katalis juga diperoleh bahwa $\mathrm{Cu}$-zeolit memiliki tingkat keasaman yang lebih besar dari zeolit. Tingkat keasaman dari katalis juga mempengaruhi efek katalitik dari katalis yang digunakan, dimana semakin besar tingkat keasaman maka semakin banyak ion $\mathrm{H}^{+}$yang dimiliki dari katalis tersebut. Hal ini juga mempengaruhi hasil dari proses esterifikasi yng menghasilkan metil ester sebagai produk reaksinya, dengan menggunakan katalis $\mathrm{Cu}$-zeolit waktu pembentukan dari metil ester lebih cepat dibandingkan dengan menggunakan zeolit, yang dapat dilihat dari waktu retensi ang dihasilkan, serta luas area yang dihasilkan lebih besar, sehingga dapat dikatakan bahwa dengan menggunakan Cu-zeolit persen pembentukan dari metil asetat pada reaksi esterifikasi antara asam asetat dengan metanol lebih besar dibandingkan dengan menggunakan katalis zeolit.

\section{Kesimpulan}

Berdasarkan hasil penelitian diperoleh simpulan bahwa sifat dasar kristal dan tingkat kristalinitas dari katalis zeolit yang telah dimodifikasi dengan pengembanan logam tembaga $(\mathrm{Cu})$ tidak mengalami perubahan. Zeolit yang telah diembankan logam $\mathrm{Cu}$ memiliki tingkat keasaman yang lebih besar yang ditandai dengan $\%$ keasaman $(\% / g)$ sebesar 1,0574 untuk $\mathrm{Cu}$-zeolit dan 0,003 untuk zeolit. Sifat ini mendukung peningkatan aktivitas pada reaksi pembentukan metil asetat yakni dari $21,92 \%$ menjadi $24,29 \%$. Meskipun peningkatan ini tergolong kecil namun hubungan antara sifat permukaan katalis asam mendukung adanya potensi pengembangann $\mathrm{Cu} /$ Zeolit untuk reaksi esterifikasi.

\section{Daftar Pustaka}

Ana Primo, Tiziana Marino, Avelino Corma, Raffaele Molinari, H.G., 2011. Efficient Visible-Light Photocatalytic Water Splitting by Minute Amounts of Gold Supported on Nanoparticulate $\mathrm{CeO} 2$ Obtained by a Biopolymer Templating Method. J. Am. Chem. Soc. 133, 6930-6933.

Asnawati, D., 2014. KARAKTERISASI KATALIS Pt-Pd/ZEOLIT ALAM REGENERASI PADA REAKSI HIDRODENITROGENASI PIRIDIN. Molekul 9, 36-43.

do Nascimento, L.A.S., Angélica, R.S., da Costa, C.E.F., Zamian, J.R., da Rocha Filho, G.N., 2011. Comparative study between catalysts for esterification prepared from kaolins. Appl. Clay Sci. 51, 267-273. 
doi:10.1016/j.clay.2010.11.030

Faghihian, H., Mohammadi, M.H., 2014. Acid activation effect on the catalytic performance of Al-pillared bentonite in alkylation of benzene with olefins. Appl. Clay Sci. 93-94, 1-7. doi:10.1016/j.clay.2014.02.026

Fatimah, I., Rubiyanto, D., Huda, T., 2014. Effect of Sulfatation on ZirconiaPillared Montmorillonite to the Catalytic Activity in MicrowaveAssisted Citronellal Conversion 2014.

Gupta, P., Paul, S., 2014. Solid acids: Green alternatives for acid catalysis. Catal. Today. doi:10.1016/j.cattod.2014.04.010

Hart, M.P., Brown, D.R., 2004. Surface acidities and catalytic activities of acidactivated clays. J. Mol. Catal. A Chem. 212, 315-321. doi:10.1016/j.molcata.2003.11.013

Kim, B.-S., Lee, S.-H., Park, Y.-T., Ham, S.W., Chae, H.-J., Nam, I.-S., 2001. Selective catalytic reduction of NOx, by propene over copper-exchanged pillared clays. Korean J. Chem. Eng. 18, 704710. doi:10.1007/BF02706390

Suseno, A., Wijayanto, W., Khanif, M., Hastuti, R., 2003. PEMBUATAN DAN KARAKTERISASI KATALIS NIKEL PADA PADATAN PENDUKUNG ZEOLIT Ahmad. J.Kim.Sains Apl. 6, 7-10.

Trisunaryanti, W., Triwahyuni, E., Sudiono, S., 2005. PREPARATION, CHARACTERIZATIONS AND MODIFICATION OF Ni-Pd / NATURAL ZEOLITE CATALYSTS. Indones. J. Chem. 5, 48-53.
Worathanakul, P., Rakpasert, N., 2016. Influence of Different Preparation Methods of Copper Loading on Na-Y Zeolite for Green Gas Emission. Int. J. Environ. Sci. Dev. 7, 885-888. doi:10.18178/ijesd.2016.7.12.899 